Aquaculture

February 2017, Volume 468, Part 1, Pages 314-325

http://dx.doi.org/10.1016/i.aquaculture.2016.10.016

http://archimer.ifremer.fr/doc/00354/46521/

(c) 2016 Elsevier B.V. All rights reserved.

\title{
Effects of fasting and re-alimentation on gill and intestinal morphology and indicators of osmoregulatory capacity in genetically selected sea bass (Dicentrarchus labrax) populations with contrasting tolerance to fasting
}

\author{
Alix Maud ${ }^{2}$, Blondeau-Bidet Eva ${ }^{3}$, Grousset Evelyse ${ }^{1}$, Shiranghi Ainaz, Vergnet Alain ${ }^{4}$, \\ Guinand Bruno ${ }^{1}$, Chatain Béatrice ${ }^{4}$, Boulo Viviane ${ }^{4}$, Lignot Jehan-Hervé ${ }^{1,{ }^{*}}$
}

${ }^{1}$ University of Montpellier, UMR MARBEC, MARBEC (IRD - Ifremer - Univ. Montpellier - CNRS), Place Eugène Bataillon, 34095 Montpellier Cedex 5, France

* Corresponding author : Jehan-Hervé Lignot, email address : jehan-herve.lignot@umontpellier.fr

maud.alix@univ-lorraine.fr ; eva.blondeau-bidet@cnrs.fr ; evelyse.grousset@univ-montp2.fr ; ainazshirangi@gmail.com ; alain.vergnet@ifremer.fr ; bruno.ginand@univ-montp2.fr ; beatrice.chatain@ifremer.fr ; viviane.boulo@ifremer.fr

\begin{abstract}
:
Fasting and refeeding occur naturally in predators but this is largely ignored when dealing with farmed fish. Therefore, the effects of 3-week fasting and re-alimentation (2.5\% of the individual body mass) were investigated using two genetically selected populations (F2 generation) of $250 \mathrm{~g}$ juvenile sea bass (Dicentrarchus labrax L.). Blood osmolarity, gill and intestinal morphology and expression of the sodium pump ( $\mathrm{Na}^{+}, \mathrm{K}^{+}$-ATPase, NKA) were studied on two phenotypes showing different degrees of body mass loss during food deprivation: one group losing body mass rapidly during fasting $(F+)$ and the other one limiting body mass loss during the same period ( $\mathrm{F}-\mathrm{)}$.

Blood osmotic pressure significantly decreases due to re-alimentation in both groups, but this is compensated in the $\mathrm{F}+$ group. In this group, gill ionocytes are smaller and less numerous, but a significantly higher NKA gene expression is noted in the gills in comparison to the F- individuals 48 and $72 \mathrm{~h}$ after re-alimentation, and also in the posterior intestine $72 \mathrm{~h}$ after re-alimentation. This most probably occurs to compensate for a higher salt intake during nutrient absorption in comparison to the F- group. Furthermore, refed F- fish absorb more lipids along the proximal anterior intestine, and take longer to digest than the F + group, and show enterocyte vacuolization in the posterior intestine.
\end{abstract}

Therefore, the two selected populations have different postprandial digestive strategies: the F- fish optimize feed efficiency first at the cost of optimal hydromineral adjustment, while the $F+$ group invests in osmoregulatory performance at the expense of digestive physiology. 


\section{Statement of relevance}

Our paper is highly relevant to the general field of commercial aquaculture. There is an increasing number of research articles dealing with fasting and refeeding in commercial fish and how to improve fish nutrition based on these physiological data and genetic selection.

\section{Highlights}

- This study focused on differences observed in the gills and intestine of two selected populations with contrasting tolerance to fasting. The two phenotypes show different degrees of body mass loss during food deprivation: one group losing body mass rapidly during fasting $(F+)$ and the other one limits body mass loss during the same period (F-). During feeding, these two phenotypes have different physiological optimization / prioritization and energetic benefits. We evidence that the fast feeders $(\mathrm{F}+)$ are also the bad fasters.

Keywords : gill ionocyte, enterocyte, morphometry, osmoregulation, sea bass, fasting, re-alimentation 


\section{Introduction}

Organisms withstand environmental stress by maintaining homeostatis through physiological and biochemical regulations. This demands trade-offs in the use of metabolic energy. In response to environmentally forced energetic trade-offs, populations adapt and reallocate metabolic energy depending on their genotypic variance (Applebaum et al., 2014). In Teleost fish for example, the regulation of ion and water compete with digestive physiology (Taylor et al., 2010; Wood et al., 2010). At different salinities, some species modify their energetic substrate as well as the energy used during nutrient absorption (Gracia-López et al., 2006). The nutritional status of the fish (fasting/fed) can also directly affect the metabolic response to salinity acclimation (Kültz and Jürss, 1991; Polakof et al., 2006). Furthermore, diet manipulation such as the addition of $\mathrm{NaCl}$ to the food can result in greater feeding efficiency and mass gain when fish are reared in freshwater, and lead to a better adaptability during transfer from fresh to saltwater (Al-Amoudi, 1987; Cnaani et al., 2012, 2010; FontaínhasFernandes et al., 2000; Gatlin III et al., 1992; Harpaz et al., 2005; Salman and Eddy, 1990).

Different mechanisms of salt and water movement in the gills, gut, kidney and through the skin (i.e. larval stages) maintain stability in the internal medium of teleosts (Varsamos et al., 2005; Whitehead, 2010). In the gills, specialized ionocytes (mitochondria-rich cells or chloride cells) play a major role in ion and water exchanges (Evans et al., 1999; Hiroi and McCormick, 2012; Lorin-Nebel et al., 2006). Similarly, the fish intestine not only regulates nutrient absorption but also ion and water exchanges (Grosell, 2010; Whittamore, 2011). It is essential for the teleost to couple high drinking rates with intestinal fluid absorption in order to compensate for the loss of water to the hyperosmotic environment. Although salt intake due to feeding in seawater does not exceed daily intake from drinking (Dabrowski, 1986; Shehadeh and Gordon, 1969), such an acute intake induces a diet-dependent challenge 
(Grosell and Taylor, 2007; Taylor et al., 2007). Despite the desalinisation occurring in the oesophagus and fluid dilution in the stomach, the luminal fluid that enters the anterior intestine remains slightly hyperosmotic in comparison to the body fluids (approximately 400$475 \mathrm{mOsm} \cdot \mathrm{kg}^{-1}$ ). It then becomes iso-osmotic along the anterior intestine (Marshall and Grosell, 2006). Water absorption occurs mainly in the proximal and middle part of the anterior intestine and is primarily associated with $\mathrm{NaCl}$ cotransport through a 'solute-linked' water transport process occurring in the lateral spaces between adjacent cells of the intestinal mucosa (Larsen et al., 2009; Thiagarajah and Verkman, 2006). Different ions are then secreted back into the gut, creating an excreted luminal fluid that is iso-osmotic to the body fluids but has a different ionic concentration. The final role of intestinal function in osmoregulation occurs in the rectum with solute-coupled water absorption (Gregorio et al., 2013).

As seen in various Vertebrates, the intestine is one of the most costly tissues to maintain (Cant et al., 1996), functionally linking energy intake and energy used. It is one of the most plastic organs which can be severely atrophied during fasting and rapidly reactivated at refeeding, even after prolonged fasting (Ali et al., 2003; Blier et al., 2007; Gas and Noailliac-Depeyre, 1976; Krogdahl and Bakke-McKellep, 2005; Lignot, 2012; McCue, 2010; Zaldúa and Naya, 2014). Teleost fish show accelerated growth ('compensatory growth') due to the enhanced feed intake, nitrogen production and feed conversion efficiency after refeeding (Ali et al., 2003; Won and Borski, 2013). Hyperphagia may not be the only factor explaining accelerated growth rate during refeeding. Optimising resource allocation between structural, storage and gonadal growth, maintenance and energy-consuming activities such as foraging and predator avoidance could also play a role (Ali et al., 2003). 
The European sea bass Dicentrarchus labrax is a eurythermic $\left(5-28^{\circ} \mathrm{C}\right)$ and euryhaline $(0 \mathrm{ppt}-$ hypersaline condition) coastal species that migrates, as juveniles and adults, between the open sea and brackish coastal lagoons (and even freshwater estuaries) for feeding. Therefore, this study was designed in order to test the energetic trade-off between digestive processes and osmoregulatory functions in two selected populations of juvenile sea bass with either high $(\mathrm{F}+)$ or low $(\mathrm{F}-)$ mass loss during fasting (Dupont-Prinet et al., 2010). We aimed to identify morphological and functional differences at the branchial and intestinal levels during fasting and throughout the postprandial period. 


\section{Materials and methods}

\subsection{First and second generations of selective breeding (Fig. 1)}

Selective breeding of the first and second generations of sea bass was carried out at IFREMER (Station Expérimentale d'Aquaculture, Palavas-les-Flots, France) between May and July 2011.

The first generation of selected sea bass was bred according to Dupont-Prinet et al., (2010). At 68 days post fertilization, sea bass were transferred to a $5 \mathrm{~m}^{3}$ fibreglass tank supplied with bio-filtered aerated seawater at $20^{\circ} \mathrm{C}$, and were fed ad libitum (self-feeder) with a standard commercial diet (Neogrower, Le Gouessant, France) containing 45\% protein and 17\% lipids. At day 306 post fertilization, 2000 fish were individually tagged by inserting a PIT-tag® (Passive Integrated Transponder, AEG-Id, Ulm, Germany) horizontally just behind the head to prevent any change of position subsequent to implantation. Fish were then reared for an additional period of four weeks following a standard rearing protocol (Chatain, 1994) before being anaesthetised (2-phenoxy-ethanol, $0.4 \mathrm{ml} . \mathrm{l}^{-1}$, Aquaveto). They were individually identified using a PIT-Tag reader, weighed to the nearest $0.1 \mathrm{~g}$ and their fork length was measured to the nearest $\mathrm{mm}$. They were then submitted to two successive cycles of threeweek food deprivation three-week ad libitum refeeding by self-feeder, with body mass and fork length measured at the end of each deprivation and refeeding period. Individuals representing $25 \%$ of the highest and lowest mass loss during fasting (labelled F+ and F-, respectively) and with the $25 \%$ highest and lowest weight gain following refeeding (labelled WG+ and WG-, respectively) were identified, as described in Grima et al. (2010a, 2010b).

For the second generation, individuals selected for extreme performance to starvation resistance $(\mathrm{F}+/ \mathrm{F}-)$ were crossed in order to obtain fertilized eggs, each group being a mix of WG+ and WG- individuals (20 males F+ x 5 females F+ and 20 males F- x 5 females F-). 
Newly-hatched larvae and young juveniles were maintained and 2000 of these fish were individually tagged at day 221 post fertilization. After an additional period of four weeks, they were anesthetised, individually identified, weighed and measured before the fasting and re-alimentation experiment.

\subsection{Fasting and re-alimentation experiments}

Fifty $\mathrm{F}+$ and $50 \mathrm{~F}$ - fish were transferred to five $3 \mathrm{~m}^{3}$ tanks (10 F+ and $10 \mathrm{~F}$ - in each tank) supplied with bio-filtered seawater at $20^{\circ} \mathrm{C}$ with a salinity of 37 g. $1^{-1}$, under a $12 \mathrm{~h}: 12 \mathrm{~h}$ light:dark photoperiod. Fish were then submitted to two successive cycles of 3-week feed deprivations and 3-week ad libitum refeeding by self-feeder (Neogrower $\mathrm{n}^{\circ} 5$ : protein $43 \%$, lipids $20 \%$, ash $5.6 \%$, fiber $3 \%$ ).

At the completion of the second 3-week fasting period, anesthetised fish were either sacrificed (2-phenoxy-ethanol, $500 \mathrm{mg} . \mathrm{l}^{-1}$, Aquaveto) for blood, branchial and intestinal tissue sampling or force-fed ( $2.5 \%$ body mass). Re-alimented fish were then left in their tanks for 4, 24, 48 or 72 hours after force feeding and then sacrificed. Blood samples were taken in heparinized syringes for blood osmotic pressure determination and measured with a micro-osmometer (Model 3300, Advanced Instruments, Needham Heights, MA, USA). Tissue samples (second gill arches, proximal and distal segments of the anterior intestine, posterior intestine) were directly transferred into either TRIzol® (ThermoFisher, 15596026), Bouin or glutaraldehyde fixatives.

Selective breeding and animal experimentation operated at the IFREMER facilities were authorized by French animal experimentation regulations (C-34-192-6). Technical staff and scientists conducted animal experiments in accordance with good animal practice under 
individual authorizations from the DDPP (Direction Départementale de la Protection des Populations - Hérault).

\subsection{Light microscopy and NKA immunolabelling}

For light and fluorescent microscopy, samples of the gills, anterior intestine (proximal and distal segments) and posterior intestine (rectum) were fixed in Bouin's solution for 48 hours, then washed in $70 \%$ alcohol and dehydrated in an ascending series of ethanol and finally processed for embedding in Paraplast X-TRA® (Sigma-Aldrich, P3808). Then, $4 \mu \mathrm{m}$ sections were cut on a Leitz Wetzlar microtome, collected on glass slides and either stained using the classical Masson's trichrome staining protocol (Martoja and Martoja-Pierson, 1967) or directly used for immunolabelling.

Prior to NKA immunolabelling, sections were immersed in Histoclear (Histological Clearing Agent, Agar, R1345) for 10 min $(2 \times 5 \mathrm{~min})$ for dewaxing, placed in butanol for $5 \mathrm{~min}$ then hydrated through a graded series of ethanol. Slides were rinsed in a solution of $10 \mathrm{mM}$ phosphate-buffered saline (PBS), $150 \mathrm{mM} \mathrm{NaCl}$ and 0,01\% Tween-20, $\mathrm{pH} \mathrm{7.3,} \mathrm{for} 10 \mathrm{~min}$

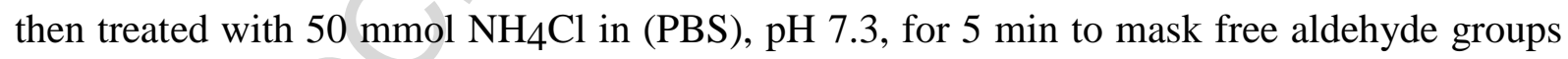
of the fixative. The sections were incubated for $10 \mathrm{~min}$ with a blocking solution (BS) containing $1 \%$ bovine serum albumin (BSA) and $0.1 \%$ gelatin in PBS. They were then left for $2 \mathrm{~h}$ at room temperature in a humidity chamber where sections were covered with the primary antibody rabbit anti-Na ${ }^{+} / \mathrm{K}^{+}$-ATPase H300 (Santa Cruz Bio-technology, USA) diluted in PBS at $10 \mu \mathrm{g} \cdot \mathrm{ml}^{-1}$. Control sections were incubated in BS without primary antibodies. After three extensive washes in BS (10 minutes per wash) to remove any unbound antibody, the sections were incubated for $1 \mathrm{~h}$ with a secondary antibody, donkey anti-rabbit (Alexa Fluor® 546), 10 $\mu \mathrm{g} \cdot \mathrm{ml}^{-1}$. After extensive washing in BS (six times for $5 \mathrm{~min}$ ), sections were mounted in $80 \%$ glycerine, $20 \%$ PBS plus 2\% N-propyl-gallate to minimize photobleaching 
(ImmunoHistoMount, Aqueous-based Media, Santa Cruz Bio-technology, USA). Stained and labelled sections were all examined using a Leitz Diaplan microscope equipped with a special filter for fluorescence and associated with a Leica DC $300 \mathrm{~F}$ digital camera and FW 4000 I software (Leica Microsystems, Rueil-Malmaison, France).

\subsection{Gene expression}

DNAse I (Invitrogen) treatment was applied to all RNA samples to prevent genomic DNA contamination. The total RNA concentration was determined by OD 260 measurements in an Eppendorf BioPhotometer (Eppendorf, Hamburg, Germany), and its purity was verified using the 260/280 absorbance ratio. The integrity and relative quantity of total RNA were checked by electrophoresis. Three point five micrograms of total RNA extracted from each group were reverse-transcribed using $500 \mu \mathrm{g} \mathrm{mL} \mathrm{mL}^{-1}$ of Oligo(dT) primer and $200 \mathrm{U}$ of M-MLV RT (Invitrogen), following the manufacturer's instructions.

We used specific primers to amplify sea bass NKA $\alpha 1$ subunit (forward: CTGGAGTGGAAGAAGGTC, position: 94-111; reverse: GATGAAGAGGAGGAAGG, position: 181-197) (Giffard-Mena et al., 2008). The qPCR reaction was performed with a Light CyclerTM 480 system version 3.5 (Roche, Mannheim, Germany) in a final volume of 5 $\mu 1$, as previously described (Giffard-Mena et al., 2008). Briefly, $2.5 \mu \mathrm{l}$ of LightcyclerFastStart DNA Master ${ }^{\text {PLUS }}$ SYBR-Green $\mathrm{I}^{\mathrm{TM}}$ Mix (Roche), $0.75 \mu \mathrm{l}$ of each forward and reverse primers $(0.5 \mu \mathrm{M})$ and $1 \mu \mathrm{l}$ of transcribed cDNA were applied. The relative expression of each gene in each tissue was calculated for 100 copies of the housekeeping gene (EF1 $\alpha$, (Nebel et al., 2005)) using the formula: $\mathrm{N}=100 \times 2$ (Ct housekeeping gene - CtXgen) (Rodet et al., 2005). EF1 $\alpha$ was used as an expression control because its mRNA expression does not change following salinity transfer (Lorin-Nebel et al., 2006; Mitter et al., 2009; Scott, 2004). 


\subsection{Transmission Electron Microscopy}

Pre-fixed samples were left in a mixture $(1: 1, \mathrm{v} / \mathrm{v})$ of $2 \%$ glutaraldehyde in $0.1 \mathrm{M}$ sodium cacodylate buffer for 24 hours then processed for transmission electronic microscopy (TEM) using a classical protocol. Post-fixation was performed in a mixture of $1 \%$ osmium tetraoxide and $0.1 \mathrm{M}$ sodium cacodylate buffer for $2 \mathrm{~h}$ at $4{ }^{\circ} \mathrm{C}$. Ethanol-dehydrated samples were then embedded in agar 100 resin (R1031, same formulation as Epon 812, Agar). Ultra-thin sections $(50-150 \mathrm{~nm})$ were cut on a LKB Bromma 8800 Ultratome®3 or OM2 ultramicrotome and contrasted with uranyl acetate and lead citrate prior to examination on a JEOL 1200 EX transmission electron microscope at $70 \mathrm{kV}$.

\subsection{Scanning electron microscopy}

After 48 hours in Bouin's solution, small tissue samples fixed in for 48 hours were washed in $70 \%$ ethanol then dehydrated through a graded ethanol series and bathed in 1,1,1,3,3,3hexamethyldisilazane before being air-dried and attached to specimen stubs with adhesive carbon tabs or silver paint. Samples were coated with palladium for 180 seconds $(\sim 40 \mathrm{~m} \AA)$ using the Edwards Sputter Coater, and examined with a FEI Quanta 200 ESEM using the conventional mode (high vacuum) and the Thornley-Everhart secondary electron detector.

\subsection{Morphometry}

Histological and immunofluorescent sections of the proximal and distal anterior intestine and gills were photographed at a magnification of 40x. Morphometrical measures were obtained using Image $\mathbf{J}$ freeware (http://rsbweb.nih.gov/ij/). For gill samples, the number of ionocytes / $100 \mu \mathrm{m}$ of linear gill filament and the area of 10 ionocytes per section were calculated (only ionocytes sectioned through their nucleus were considered). Within the intestine, the length of 
the enterocytes was measured from the basal membrane of the cells up to the base of the apical microvilli. Seven to ten fish were used for each group and nutritional condition.

\subsection{Statistics}

Analysis of variance (2-way ANOVA) was used to determine any significant differences according to the postprandial status of the fish (time) and between populations ( $\mathrm{F}+$ and $\mathrm{F}-$ ). The effects of sampling time on enterocyte length, ionocyte surface area and number were tested using post-hoc planned pairwise mean comparisons between sampling periods (SNK a posteriori tests). Data are presented as means \pm 1 SEM, and the level of statistical significance was set at $p<0.05$. Statistical analyses were performed using the software package Statistica 12.0 (Statsoft Inc., Tulsa, Oklahoma, US). 


\section{Results}

\subsection{Blood osmolality}

Blood osmolality values for the different fasting (T0) and re-alimented populations (T4, T24, T48, T72) are presented in Figure 2. A significant feeding effect is observed for both F+ and F- populations (ANOVA, $p<0.05$ ). Blood osmolalities decrease significantly from 370-380 mOms.kg ${ }^{-1}$ in fasting fish and 4 hours after re-alimentation to $350-360 \mathrm{mOms} \cdot \mathrm{kg}^{-1}$ at 48 and 72 hours post re-alimentation. For the $\mathrm{F}+$ population, a significant increase in blood osmotic pressure is observed at 72 hours after re-alimentation. Osmotic pressure values for this $\mathrm{F}+$ fish population at 72 hours after re-alimentation are similar to those measured in fasting fish. However, osmotic pressure values of the $\mathrm{F}+$ population are significantly different compared to those of the 72 hours post re-alimented F- population.

\subsection{NKA expression in the gills, proximal and distal anterior intestine}

The transcript levels of NKA in the branchial ionocytes and intestinal segments of F+ and Fpopulations were quantified, and the relative expressions are presented in Figure 3. Compared to fasting individuals, a 3-fold increase in the NKA transcript level is observed in the gills for the re-alimented $\mathrm{F}+$ population, while a significantly lower transcript level is observed in the re-alimented F- population (Fig. 3A). In the anterior intestine (proximal and distal segments), no difference could be observed between the different nutritional conditions or between the 2 genetically selected populations (Fig. 3B, 3C). In the posterior intestine, the NKA transcript level only increased significantly 72 hours post re-alimentation in the $\mathrm{F}+$ population (Fig. 3D). 
In the gills, the immunolocalisation of the NKA indicates the presence of the enzyme in the ionocytes of the F+ and F- populations. These ionocytes are located between the lamellae and along the primary filaments of the gills (Fig. 4A-F). In the $48 \mathrm{~h}$ and $72 \mathrm{~h}$ post re-alimented Fpopulation, some of the labelled ionocytes are also present at the base of the gill lamellae. The number and size of the ionocytes are higher in the gills of the F-population compared to the F+ population (Fig. 4G and 4H). However, no difference could be detected between the fasted fish (T0) and the re-alimented groups (48h and 72h) in either population (Fig. 4H).

\subsection{Morphology of the intestine (proximal and distal anterior intestine, rectum)}

The midgut and hindgut regions, i.e. the anterior (about $80 \%$ of the total length) and posterior intestine, or rectum (about $20 \%$ of the total length) are separated by a constriction (valvula), as illustrated in Fig. 5A. Five intestinal caeca are also connected to the proximal anterior intestine. Along the mucosal side, the intestinal wall is folded in order to increase its surface area. Extended primary and secondary folds are visible in the proximal anterior segment (Fig 5B), and primary folds in the distal part of the anterior intestine are longitudinally elongated with short secondary folds (Fig. 5C, 7A), whilst only meandrous primary folds can be seen in the posterior intestine (Fig. 8A).

In fasting animals, the proximal segment of the anterior intestine has extremely thin and atrophied folds, and lacks some secondary folds (Fig. 5D, 6A). Within the epithelial layer, enterocytes appear thin, elongated and aligned (Fig. 6D). Some primary and secondary folds elongate rapidly $4 \mathrm{~h}$ after re-alimentation (Fig. 6B) and the entire intestinal lining becomes swollen 24 to 72 hours post re-alimentation (Fig. 6C) due to the presence of numerous lipid droplets within the enterocytes (Fig. 6E, 6F). These free lipid droplets can fill the cells, while the lateral spaces between enterocytes located close to the basal side of the epithelium widen 
due to chylomicrons passing through the lamina propria into the general circulation system (Fig. 6F). All these lipids entering through the intestinal epithelium temporarily accumulate within the submucosa tunica at the base of the folds, where the conjunctive tissue appears dilated (Fig. 5E). Cracks were observed along the thin edges of the intestinal folds of post realimented individuals (Fig. 6G, 6H), but these are considered to be artifacts occurring during sample preparation (dehydration of the samples causing lipid extrusion where lipid droplets are the biggest and/or the most numerous).

In the distal segment of the anterior intestine, fasting animals possess elongated primary folds (Fig. 5C) that become highly convoluted in re-alimented individuals (Fig. 7A). Some enterocytes have atrophied apical microvilli (Fig. 7B). In re-alimented animals, the brush border appears thicker (Fig. 7C). In fasted and re-alimented animals, the monolayered epithelium possesses numerous goblet cells and tightly packed absorbent enterocytes (Fig. 7D). In the distal segment of the anterior intestine, re-alimented animals do not have large lipid droplets (as seen in the proximal part of the anterior intestine), although enlarged intercellular spaces could be observed (Fig. 7E). Finally, whatever the nutritional conditions considered, no difference could be observed between the F+ and F- populations.

In the posterior intestine, meandrous folds of re-alimented animals (Fig. 8A) possess numerous goblet cells and absorbing enterocytes with supra-nuclear vacuoles (Fig. 8B, 8C, 8D). These apical vacuoles are absent in fasting animals (data not shown). Furthermore, there is a striking difference between the F+ and F- groups: these vacuoles are located at the tip of the folds and are relatively small and granular in the F- individuals (Fig. 8B), and although some F+ individuals have similar vacuoles, most of the analyzed fish have enlarged, ovoid 
vacuoles (Fig. 8C, 8D), some filled with dense material (Fig. 8C, 8D). These vacuoles are located in most of the intestinal folds but are not found at their base (Fig. 8C).

\subsection{Epithelium morphometry of the proximal and distal anterior intestine}

Measurements of the thickness of the brush border and the length and width of the enterocytes along the proximal and distal segments of the anterior intestine are presented in Figure 9. For both populations, the enterocytes significantly elongate and become larger with realimentation in the proximal segment of the anterior intestine (Fig. 9A, 9C). At 48h post realimentation, the F- populations also have significantly longer cells $(p<0.05$, Fig 9A). Enterocytes in the distal segment do not respond to the different nutritional conditions (Fig. 9B, 9D) except in the $\mathrm{F}+$ population, where longer cells were observed during fasting compared to cells in re-alimented individuals $(p<0.05$; Fig. 9B). Furthermore, the microvilli do not react to these nutritional conditions in the proximal part of the anterior intestine (Fig. 9A), but elongate slightly with re-alimentation in the distal end of the anterior intestine (Fig. 9B). 


\section{Discussion}

This study shows that the anterior intestine of two sea bass sub-populations with contrasting tolerance toward food deprivation, presented a similar atrophy of the mucosal and submucosal layers after three weeks of fasting. A dense cytoplasm was observed in the epithelial enterocytes in fasting fish, whilst these cells were filled with large and numerous lipid droplets in re-alimented fish. The epithelium appeared to be at its thickest 48 hours after realimentation due to this lipidic charge. Lipids also accumulated within the connective tissue of the submucosal layer. As seen in other Teleost fish, this lipid 'wave' is limited to the proximal segment of the anterior intestine and pyloric caeca (Bauermeister et al., 1979; Gauthier and Landis, 1972; Sire et al., 1981). Surprisingly, fasting and re-alimentation did not modify the length of the microvilli. This could be due to the limited fasting period but could also be interpreted as a means to optimize refeeding in the eventuality of a prey being captured. However, there is a differential postprandial response between the two subpopulations. Fewer lipids enter the enterocytes in the proximal anterior intestine for the $\mathrm{F}+$ fish, i.e. those with a high mass loss during fasting (the least tolerant to food deprivation), compared to the F-population. Although the increased cell width and the slight increase in brush border thickness due to re-alimentation do not differ between the two groups, the lengthening of the enterocytes, however, is strikingly different between the two fish groups, and is most probably due to the higher lipid accumulation within the cells of the Fpopulation. We also note that the distal segment of the anterior intestine appears more flexible compared to the proximal segment, with a feeding-induced lengthening of the brush border but an overall decreased cell volume in re-alimented individuals compared to fasting fish (reduced cell length but no change for the cell width). Finally, in the posterior intestine, where absorption of protein macromolecules by pinocytosis occurs, a clear morphological change is 
observed between the two sub-populations. Most individuals of the F+ population have enlarged ovoid supra-nuclear vacuoles, some filled with dense material. Similar enlarged vacuoles have already been observed in farm-reared sea bass overfed with artificial feed (Deplano et al., 1991). It is thus hypothesized that the F+ group is not as efficient in feed assimilation as the F- group. The F+ fish may also suffer from an overload of water and ions entering the cells. As seen in other seawater teleosts such as eels and seabream, the rectum greatly contributes to the simultaneous water and ion absorption through the intestine (Gregorio et al., 2013; Kim et al., 2008).

Re-alimentation also strongly affects blood osmolality, as evidenced by the sharp decrease occurring in both groups within 48 hours after feeding. This must involve a higher hypoosmotic work for these fish, which are maintained in seawater. The bulk of water and ions entering into the extracellular fluids during re-alimentation must be counterbalanced through the gills and the kidney (Evans et al., 1999). While this increased work is subsequently compensated in the F+ group, it is still imbalanced in the F- group, where blood osmolalities remain low 72 hours after re-alimentation. This difference in osmoregulatory capacity observed in fed fish might be due to the morpho-functional differences observed in the gills, as F- individuals have larger and more numerous gill ionocytes than the F+ individuals. Ionocyte hyperplasia and hypertrophy could therefore be a functional attempt to optimize gill osmotic efficiency. Furthermore, higher NKA expression is observed in the gills of the F+ group. NKA is mostly present in gill ionocytes and generates a strong electrochemical gradient through the cell, i.e., between the apical and basal membranes, in order to actively transport ions. This postprandial increase in NKA transcript levels was observed in the gills but also in the posterior intestine of individuals in the F+ group, and could facilitate a fast return to higher blood osmotic pressure values in this group compared to the F- group. 
In conclusion, the differences observed between the two selected populations in the gills and intestine clearly indicate different physiological optimization / prioritization and energetic benefits through different physiological strategies. The differing osmotic performance in the gills could partially explain the different time sequences observed for the postprandial digestive processes between the two groups. Superior osmotic performance of the F+ group could alter their digestive processes in comparison to the F- fish. Reducing the postprandial period could also minimize predation risk and optimize refeeding possibilities, but may also affect energy reserve processes. Conversely, the extended digestive processes observed in Findividuals could enhance feed efficiency at the expense of a rapid adjustment of the internal hydromineral balance. This could lead to more efficient management of energy resource and improved fasting capacities, as these fish are better suited to minimizing mass loss during fasting.

In order to fully characterize these phenotypic differences, it would be advantageous to determine NKA activity in these different organs and to focus on water movements. It would also be interesting to evaluate the two sub-group growth rates after repeated fasting / refeeding periods in order to verify whether the F- group can better direct energy towards growth at the expense of osmoregulating capacities, and to analyse their body composition, paying particular attention to storage organs such as muscle and the liver. Finally, it would be relevant to test whether the $\mathrm{F}+$ group is better suited to drastic salinity changes during the postprandial period than the F- group.

\section{Competing interest}

The authors declare that they have no competing interests. 


\section{Acknowledgements}

This research was funded by the French Ministry of Agriculture and Fisheries and is a continuation of the REGULBASS project from the French National Agency. We greatly appreciate the work on selective sea bass breeding performed at the Ifremer Experimental Research Station and by Dr M. Vandeputte.

\section{References}

Al-Amoudi, M.M., 1987. The effect of high salt diet on the direct transfer of Oreochromis mossambicus, O. spilurus and O. aureus/O. niloticus hybrids to sea water. Aquaculture 64, 333-338.

Ali, M., Nicieza, A., Wootton, R.J., 2003. Compensatory growth in fishes: a response to growth depression. Fish Fish. 4, 147-190.

Applebaum, S.L., Pan, T.-C.F., Hedgecock, D., Manahan, D.T., 2014. Separating the Nature and Nurture of the Allocation of Energy in Response to Global Change. Integr. Comp. Biol. 54, 284-295. doi:10.1093/icb/icu062

Bauermeister, A.E., Pirie, B.J., Sargent, J.R., 1979. An electron microscopic study of lipid absorption in the pyloric caeca of rainbow trout (Salmo gairdnerii) fed wax ester-rich zooplankton. Cell Tissue Res. 200, 475-486.

Blier, P.U., Dutil, J.-D., Lemieux, H., Bélanger, F., Bitetera, L., 2007. Phenotypic flexibility of digestive system in Atlantic cod (Gadus morhua). Comp. Biochem. Physiol. A. Mol. Integr. Physiol. 146, 174-179. doi:10.1016/j.cbpa.2006.10.012

Cant, J.P., McBride, B.W., Croom, W.J., 1996. The regulation of intestinal metabolism and its impact on whole animal energetics. J. Anim. Sci. 74, 2541-2553.

Chatain, B., 1994. Abnormal swimbladder development and lordosis in sea bass (Dicentrarchus labrax) and sea bream (Sparus auratus). Aquaculture 119, 371-379. 
Cnaani, A., Barki, A., Slosman, T., Scharcanski, A., Milstein, A., Harpaz, S., 2010. Dietary salt supplement increases the growth rate in freshwater cultured tilapia hybrids. Aquac. Res. doi:10.1111/j.1365-2109.2009.02438.x

Cnaani, A., Stavi, A., Smirnov, M., Harpaz, S., 2012. Rearing White Grouper (Epinephelus aeneus) in Low Salinity Water: Effects of Dietary Salt Supplementation. Isr. J. Aquac.-Bamidgeh.

Dabrowski, K.R., 1986. Ontogenetical aspects of nutritional requirements in fish. Comp. Biochem. Physiol. A Physiol. 85, 639-655.

Deplano, M., 1989. Etude morpho-fonctionnelle de la muqueuse intestinale du loup Dicentrarchus labrax L: mise en évidence de pathologies nutritionnelles chez les sujets immatures et chez les larves. Université de Montpellier 2, Montpellier.

Deplano, M., Connes, R., Diaz, J.P., others, 1991. Postvalvular enterocytes in feral and farmreared sea bass Dicentrarchus labrax: hypervacuolization related to artificial feed. Dis. Aquat. Org. 11, 9-18.

Dupont-Prinet, A., Chatain, B., Grima, L., Vandeputte, M., Claireaux, G., McKenzie, D.J., 2010. Physiological mechanisms underlying a trade-off between growth rate and tolerance of feed deprivation in the European sea bass (Dicentrarchus labrax). J. Exp. Biol. 213, 1143-1152. doi:10.1242/jeb.037812

Evans, D.H., Piermarini, P.M., Potts, W.T.W., 1999. Ionic transport in the fish gill epithelium. J. Exp. Zool. 283, 641-652.

Fontaínhas-Fernandes, A., Monteiro, M., Gomes, E., Reis-Henriques, M.A., Coimbra, J., 2000. Effect of dietary sodium chloride acclimation on growth and plasma thyroid hormones in tilapia Oreochromis niloticus (L.) in relation to sex. Aquac. Res. 31, 507517. 
Gas, N., Noailliac-Depeyre, J., 1976. Studies on intestinal epithelium involution during prolonged fasting. J. Ultrastruct. Res. 56, 137-151.

Gatlin III, D.M., MacKenzie, D.S., Craig, S.R., Neill, W.H., 1992. Effects of dietary sodium chloride on red drum juveniles in waters of various salinities. Progress. Fish-Cult. 54, $220-227$.

Gauthier, G.F., Landis, S.C., 1972. The relationship of ultrastructural and cytochemical features to absorptive activity in the goldfish intestine. Anat. Rec. 172, 675-701.

Giffard-Mena, I., Lorin-Nebel, C., Charmantier, G., Castille, R., Boulo, V., 2008. Adaptation of the sea-bass (Dicentrarchus labrax) to fresh water: Role of aquaporins and $\mathrm{Na}+\mathrm{K}+-$ ATPases. Comp. Biochem. Physiol. A. Mol. Integr. Physiol. 150, 332-338. doi:10.1016/j.cbpa.2008.04.004

Gracia-López, V., Rosas-Vázquez, C., Brito-Pérez, R., 2006. Effects of salinity on physiological conditions in juvenile common snook Centropomus undecimalis. Comp. Biochem. Physiol. A. Mol. Integr. Physiol. 145, 340-345. doi:10.1016/j.cbpa.2006.07.008

Gregorio, S.F., Carvalho, E.S.M., Encarnacao, S., Wilson, J.M., Power, D.M., Canario, A.V.M., Fuentes, J., 2013. Adaptation to different salinities exposes functional specialization in the intestine of the sea bream (Sparus aurata L.). J. Exp. Biol. 216, 470-479. doi:10.1242/jeb.073742

Grima, L., Chatain, B., Ruelle, F., Vergnet, A., Launay, A., Mambrini, M., Vandeputte, M., 2010a. In search for indirect criteria to improve feed utilization efficiency in sea bass (Dicentrarchus labrax). Aquaculture 302, 169-174.

doi:10.1016/j.aquaculture.2010.02.016 
Grima, L., Vandeputte, M., Ruelle, F., Vergnet, A., Mambrini, M., Chatain, B., 2010b. In search for indirect criteria to improve residual feed intake in sea bass (Dicentrarchus labrax). Aquaculture 300, 50-58. doi:10.1016/j.aquaculture.2010.01.003

Grosell, M., 2010. The role of the gastrointestinal tract in salt and water balance, in: Fish Physiology: The Multifunctional Gut of Fish. M. Grosell, T. Farrell, and C. Brauner, London, pp. 135-164.

Grosell, M., Taylor, J.R., 2007. Intestinal anion exchange in teleost water balance. Comp. Biochem. Physiol. A. Mol. Integr. Physiol. 148, 14-22. doi:10.1016/j.cbpa.2006.10.017

Harpaz, S., Hakim, Y., Slosman, T., Eroldogan, O.T., 2005. Effects of adding salt to the diet of Asian sea bass Lates calcarifer reared in fresh or salt water recirculating tanks, on growth and brush border enzyme activity. Aquaculture 248, 315-324.

doi:10.1016/j.aquaculture.2005.03.007

Hiroi, J., McCormick, S.D., 2012. New insights into gill ionocyte and ion transporter function in euryhaline and diadromous fish. Respir. Physiol. Neurobiol. 184, 257-268. doi:10.1016/j.resp.2012.07.019

Kim, Y.K., Ideuchi, H., Watanabe, S., Park, S. il, do Huh, M., Kaneko, T., 2008. Rectal water absorption in seawater-adapted Japanese eel Anguilla japonica. Comp. Biochem. Physiol. A. Mol. Integr. Physiol. 151, 533-541. doi:10.1016/j.cbpa.2008.07.016

Krogdahl, Å., Bakke-McKellep, A.M., 2005. Fasting and refeeding cause rapid changes in intestinal tissue mass and digestive enzyme capacities of Atlantic salmon (Salmo salar L.). Comp. Biochem. Physiol. A. Mol. Integr. Physiol. 141, 450-460. doi:10.1016/j.cbpb.2005.06.002 
Kültz, D., Jürss, K., 1991. Acclimation of chloride cells and Na/K-ATPase to energy deficiency in tilapia (Oreochromis mossambicus). Zool. Jahrb. Abt. Für Allg. Zool. Physiol. Tiere 95, 39-50.

Larsen, E.H., Willumsen, N.J., Møbjerg, N., Sørensen, J.N., 2009. The lateral intercellular space as osmotic coupling compartment in isotonic transport. Acta Physiol. 195, 171186. doi:10.1111/j.1748-1716.2008.01930.x

Lignot, J.-H., 2012. Changes in form and function of the gastrointestinal tract during starvation: from pythons to rats, in: Comparative Physiology of Fasting, Starvation, and Food Limitation. Springer, Berlin Heidelberg, pp. 217-236.

Lorin-Nebel, C., Boulo, V., Bodinier, C., Charmantier, G., 2006. The Na+/K+/2Clcotransporter in the sea bass Dicentrarchus labrax during ontogeny: involvement in osmoregulation. J. Exp. Biol. 209, 4908-4922. doi:10.1242/jeb.02591

Marshall, W.S., Grosell, M., 2006. Ion transport, osmoregulation, and acid-base balance, in: The Physiology of Fishes. pp. 177-230.

Martoja, R., Martoja-Pierson, M., 1967. Initiation aux techniques de l'histologie animale, Masson. ed. Masson, Paris.

McCue, M.D., 2010. Starvation physiology: reviewing the different strategies animals use to survive a common challenge. Comp. Biochem. Physiol. A. Mol. Integr. Physiol. 156, $1-18$.

Mitter, K., Kotoulas, G., Magoulas, A., Mulero, V., Sepulcre, P., Figueras, A., Novoa, B., Sarropoulou, E., 2009. Evaluation of candidate reference genes for QPCR during ontogenesis and of immune-relevant tissues of European seabass (Dicentrarchus labrax). Comp. Biochem. Physiol. B Biochem. Mol. Biol. 153, 340-347. doi:10.1016/j.cbpb.2009.04.009 
Nebel, C., Nègre-Sadargues, G., Blasco, C., Charmantier, G., 2005. Morphofunctional ontogeny of the urinary system of the European sea bass Dicentrarchus labrax. Anat. Embryol. (Berl.) 209, 193-206. doi:10.1007/s00429-004-0438-6

Polakof, S., Arjona, F.J., Sangiao-Alvarellos, S., Martín del Río, M.P., Mancera, J.M., Soengas, J.L., 2006. Food deprivation alters osmoregulatory and metabolic responses to salinity acclimation in gilthead sea bream Sparus auratus. J. Comp. Physiol. B 176, 441-452. doi:10.1007/s00360-006-0065-Z

Rodet, F., Lelong, C., Dubos, M.-P., Costil, K., Favrel, P., 2005. Molecular cloning of a molluscan gonadotropin-releasing hormone receptor orthologue specifically expressed in the gonad. Biochim. Biophys. Acta BBA - Gene Struct. Expr. 1730, 187-195. doi:10.1016/j.bbaexp.2005.05.012

Salman, N., Eddy, F., 1990. Increased sea-water adaptability of non-smolting rainbow trout by salt feeding. Aquaculture 86, 259-270.

Scott, G.R., 2004. Changes in gene expression in gills of the euryhaline killifish Fundulus heteroclitus after abrupt salinity transfer. Am. J. Physiol. Cell Physiol. 287, C300C309. doi:10.1152/ajpcell.00054.2004

Shehadeh, Z.H., Gordon, M.S., 1969. The role of the intestine in salinity adaptation of the rainbow trout, Salmo gairdneri. Comp. Biochem. Physiol. 30, 397-418.

Sire, M.-F., Lutton, C., Vernier, J.-M., 1981. New views on intestinal absorption of lipids in teleostean fishes: an ultrastructural and biochemical study in the rainbow trout. J. Lipid Res. 22, 81-94.

Taylor, J.R., Mager, E.M., Grosell, M., 2010. Basolateral NBCe1 plays a rate-limiting role in transepithelial intestinal $\mathrm{HCO} 3$ - secretion, contributing to marine fish osmoregulation. J. Exp. Biol. 213, 459-468. doi:10.1242/jeb.029363 
Taylor, J.R., Whittamore, J.M., Wilson, R.W., Grosell, M., 2007. Postprandial acid-base balance and ion regulation in freshwater and seawater-acclimated European flounder, Platichthys flesus. J. Comp. Physiol. B 177, 597-608. doi:10.1007/s00360-007-0158-3

Thiagarajah, J., Verkman, A., 2006. Water transport in the gastrointestinal tract, in: Physiology of the Gastrointestinal Tract. Johnson LR, Barrett K, Ghishan F, Manchant J, Said H, Wood J, New York, pp. 1827-1845.

Varsamos, S., Nebel, C., Charmantier, G., 2005. Ontogeny of osmoregulation in postembryonic fish: A review. Comp. Biochem. Physiol. A. Mol. Integr. Physiol. 141, 401-429. doi:10.1016/j.cbpb.2005.01.013

Whitehead, A., 2010. The evolutionary radiation of diverse osmotolerant physiologies in killifish (Fundulus sp.). Evolution 64, 2070-2085. doi:10.1111/j.15585646.2010.00957.x

Whittamore, J.M., 2011. Osmoregulation and epithelial water transport: lessons from the intestine of marine teleost fish. J. Comp. Physiol. B 182, 1-39. doi:10.1007/s00360011-0601-3

Won, E.T., Borski, R.J., 2013. Endocrine Regulation of Compensatory Growth in Fish. Front. Endocrinol. 4. doi:10.3389/fendo.2013.00074

Wood, C.M., Bucking, C., Grosell, M., 2010. Acid-base responses to feeding and intestinal Cl- uptake in freshwater- and seawater-acclimated killifish, Fundulus heteroclitus, an agastric euryhaline teleost. J. Exp. Biol. 213, 2681-2692. doi:10.1242/jeb.039164 Zaldúa, N., Naya, D.E., 2014. Digestive flexibility during fasting in fish: A review. Comp. Biochem. Physiol. A. Mol. Integr. Physiol. 169, 7-14. doi:10.1016/j.cbpa.2013.12.006 


\section{Figure legends:}

Figure 1: Specific breeding and experimental design. A: first generation. 2000 individually tagged fish were tested with fasting and refeeding challenges ( 2 challenges of 3 weeks of starvation and 3 weeks of refeeding). This allowed us to screen (B) individuals that rapidly lose body mass $(\mathrm{F}+)$ versus those limiting wet mass loss (F-) and also, those that have a high/low weight gain following refeeding (WG+/WG-), respectively. C: the second generation of F+/F- individuals was crossed, and each group combined WG+ and WGindividuals (20 sires and 5 dams for each F+ and F- groups). Offspring (2000 fish with an equal representation of the different families used) were individually tagged at day 221 post fertilization and transferred to a common tank, then raised until they reached a weight of $50 \mathrm{~g}$. Two successive challenges of 3 weeks of starvation and 3 weeks of refeeding followed and at the completion of the last fasting period, 20 fasting fish $(10 \mathrm{~F}+$ and $10 \mathrm{~F}-)$ were sampled while the others were force-fed ( $2.5 \%$ body mass). These fish were transferred into 5 different tanks $(10 \mathrm{~F}+$ and 10F- in each) and were sampled 4, 24, 48 and 72 hours after force-feeding, with one tank of mixed fish being used for each of the postprandial periods considered. This experimental design benefits the advantages of gathering maximum genetic and phenotypic divergences (extreme parent for the trait and extreme performance during starvation and refeeding challenges).

Figure 2: Osmotic blood pressure (in mOsm./kg) for the F+ and F-populations in fasting and fed animals 4, 24, 48 and 72 hours post re-alimentation. Note the significant decrease in blood osmotic pressure at T48 and T72 after re-alimentation compared to fasting fish (T0), $\mathrm{T} 4$ and T24 and the significant difference (asterisk) between $72 \mathrm{~h}$ re-alimented $\mathrm{F}+$ and F- 
groups. Small and capital letters indicate a significant difference $(p<0.05)$ with $\mathrm{T} 0$ for the $\mathrm{F}+$ and F- populations, respectively.

Figure 3: NKA expression in the gills (A), proximal and distal anterior intestine (B, C), and posterior intestine (rectum) (D) for fasting fish (T0) and refed fish. Note the significant increase in NKA transcript levels for F+ refed fish in the gills while the F- refed fish present lower transcript levels than fasting fish. No change was detected in the anterior intestine, while the $\mathrm{F}+$ transcript level is significantly higher in the rectal segment for the $72 \mathrm{~h}$ refed fish.

Figure 4: NKA immunolocalisation in transversal gill sections (A-F), number of ionocytes / $100 \mu \mathrm{m}$ of gill filament (G) and area of the ionocytes in $\mu \mathrm{m}^{2}(\mathrm{H}) . \mathrm{A}, \mathrm{C}$ and $\mathrm{E}$ : $\mathrm{F}+$ individuals; B, D and F: F- individuals. A, B: 3-week fasting individuals (T0); C, D: 48h post re-alimentation; E, F: 72h post re-alimentation animals.

Note the presence of NKA-labelled ionocytes along the gill filament at the base of the gill lamellae. For the F+ 48 and $72 \mathrm{~h}$ re-alimented fish some ionocytes are also within the gill lamellae. The number and size of the F- fasting and re-alimented fish are both higher than in the $\mathrm{F}+$ population.

Figure 5: Intestinal morphology of fed (A, B, C, E) and fasting (D) individuals. A: macroscopic view of the intestine cut longitudinally (modified from Deplano, 1989). B: scanning electron micrograph of the internal surface of the proximal anterior intestine with primary and secondary folds. C: SEM image of the internal surface of the distal anterior intestine with primary folds aligned longitudinally. B, C: fed animals (48h post-realimentation). D, E: cross sections of the proximal anterior intestine in a fasting individual (D) 
and a $48 \mathrm{~h}$ post re-alimented animal (E). Note the reduced size of the folds in the fasting condition and the elongated folds in the re-alimented animal with dilated conjunctive tissue at the base of the folds (submucosa tunica). DAI: distal anterior intestine; L: gut lumen; LC: lipidic cupule; M: muscle layer; PAI: proximal anterior intestine, PC: pyloric caeca; PF: primary fold; PI: posterior intestine (rectum); SF secondary fold; Va: valvula.

Figure 6: Morphology of the proximal anterior intestine of fasting (A, D) and realimented individuals (B, C, E, F, G) of the F+ population. A, B, C, G, H: Scanning electron micrographs. D, E: light microscopy images stained with Masson's trichrome staining. F: Transmission electron micrograph. Primary and secondary folds are atrophied in fasting animals (A) but widen soon after re-alimentation (B: 4 hours after re-alimentation), and secondary folds appear swollen 48 hours after re-alimentation (C). The epithelium remains monolayered in fasting animals, with dense cytoplasm and collapsed intercellular spaces (D). This is also evident in re-alimented animals, but the cytoplasm is filled with lipid droplets (E, F) moving from the apical brushborder down to the basal side of the enterocytes (below the nuclei) and then into the lateral spaces (F). Scanning electron micrographs of realimented individuals also reveal cracks along the thin edges of the intestinal folds. These are due to artefactual lipid extrusion occurring during sample preparation $(\mathrm{G}, \mathrm{H})$. L: gut lumen; LD: lipidic droplet; LS: lateral space; M: microvilli; N: nucleus.

Figure 7: Morphology of the distal anterior intestine of fasting (A, B, D) and realimented individuals $(\mathbf{C}, \mathbf{E})$ of the $\mathbf{F}+$ population. A, B, C: scanning electron micrographs. D, E: light microscopy images stained with Masson's trichrome staining. Primary folds are highly convoluted (A). In fasting individuals, some enterocytes possess atrophied apical microvilli (B). In re-alimented animals however, the brush border appears thicker (C). In 
fasting animals, the monolayered epithelium possesses numerous goblet cells and tightly packed absorbent enterocytes (D). In re-alimented animals, the monolayered epithelium has enlarged intercellular spaces but large lipid droplets are not observed in the cytoplasm of the absorbing enterocytes, as observed in the proximal part of the anterior intestine. DE: depressed enterocyte; GC: goblet cell; ML: mucous layer.

Figure 8: Morphology of the posterior intestine of fasting (A) and re-alimented (48h) individuals $(\mathrm{B}, \mathrm{C}, \mathrm{D})$ of the $\mathrm{F}+$ population $(\mathrm{A}, \mathrm{B})$ and $\mathrm{F}$ - population $(\mathrm{C}, \mathrm{D})$. A: scanning electron micrographs. B, C, D: light microscopy images stained with Masson's trichrome staining. Convoluted folds do not possess secondary folds (A) and the absorbing enterocytes of re-alimented animals possess supra-nuclear vacuoles $(\mathrm{B}, \mathrm{C}, \mathrm{D})$ that are not present in fasting animals (data not shown). In the F- individuals, these supra-nuclear vacuoles are located at the tip of the folds and are relatively small and granular (B). Although some F+ individuals present similar characteristics, the majority, however, have larger, ovoid supranuclear vacuoles $(C, D)$, some filled with dense material $(D$, arrowhead). These vacuoles are located in most of the intestinal folds but are not found at their base (C). GC: goblet cell; SNV: supra-nuclear vacuoles.

Figure 9: Thickness of the brush border $(A, B)$, cell length $(A, B)$ and width $(C, D)$ of the enterocytes of the proximal $(\mathrm{A}, \mathrm{C})$ and distal $(\mathrm{B}, \mathrm{D})$ anterior intestine in fasting and realimented individuals of experimental groups F+ and F-. Note that for both populations, cell hypertrophy occurs mostly $48 \mathrm{~h}$ and $72 \mathrm{~h}$ after re-alimentation and is due to cell lengthening in the proximal part of the anterior intestine. Mean values with different letters are significantly different $(p<0.05)$. 


\section{Figure 1}

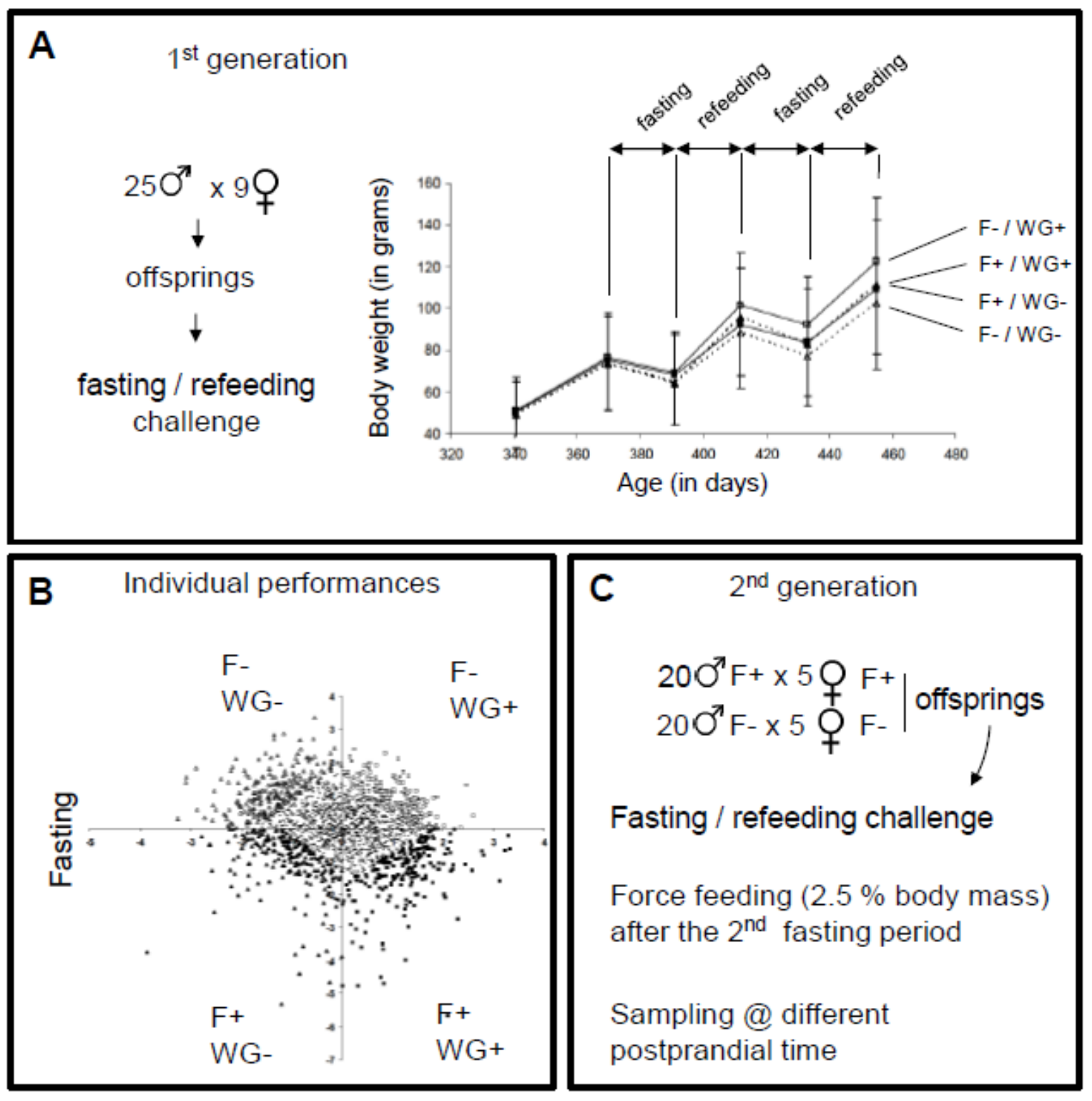


Figure 2

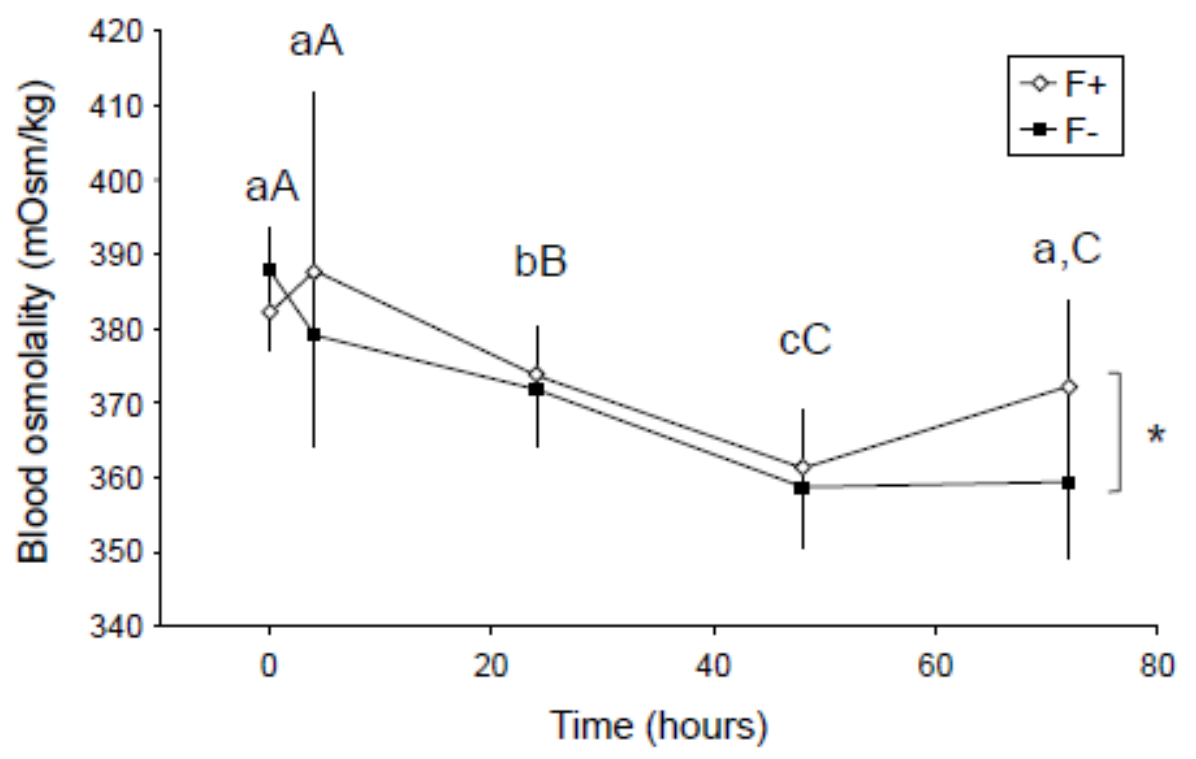




\section{Figure 3}

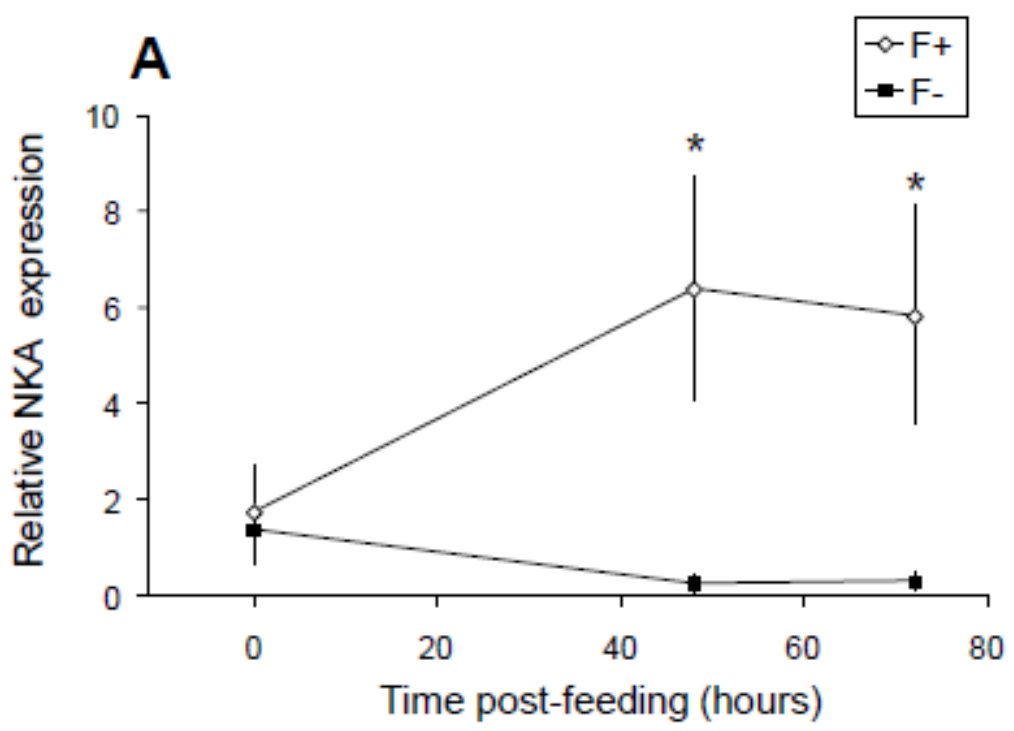

\section{B}
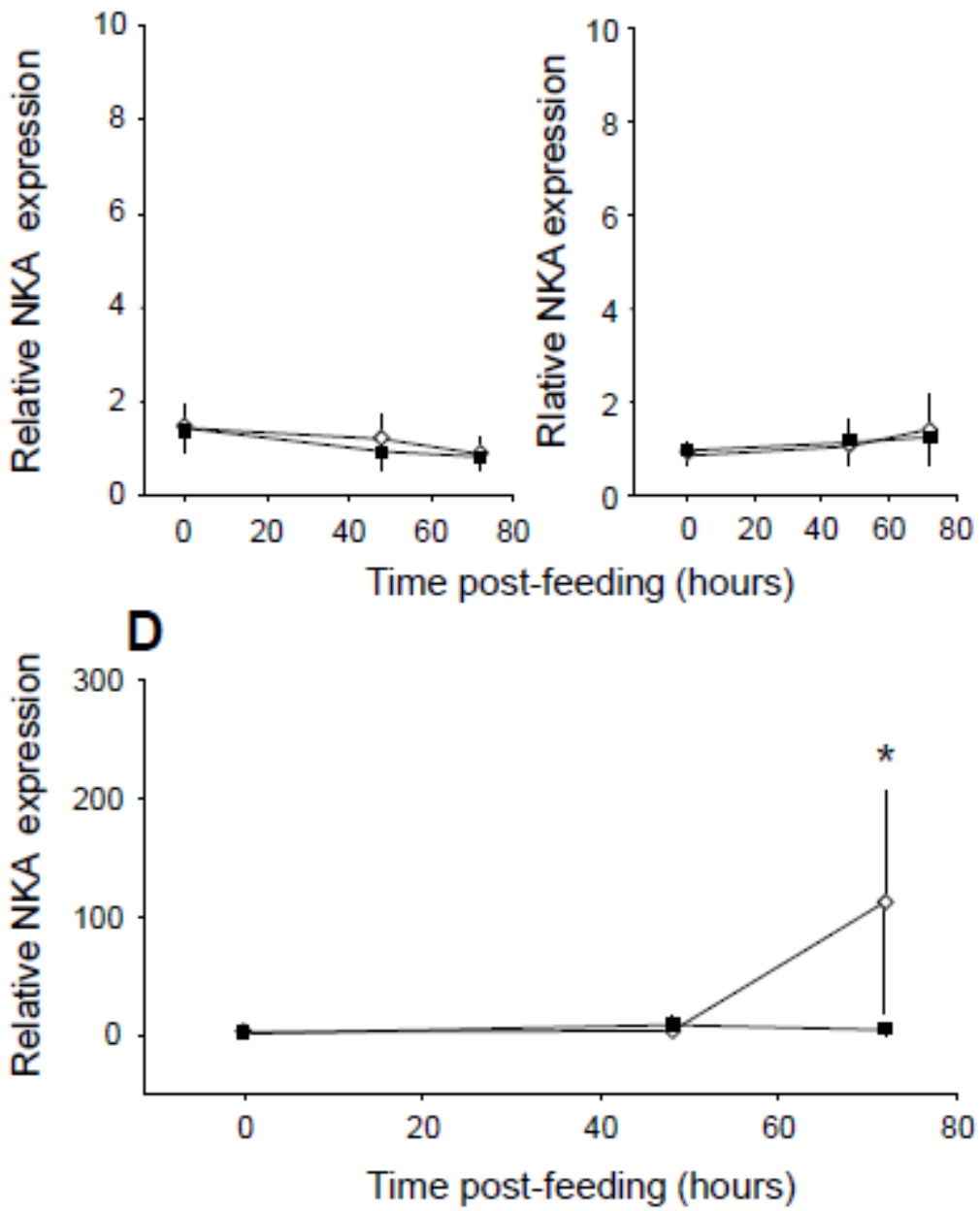
Figure 4

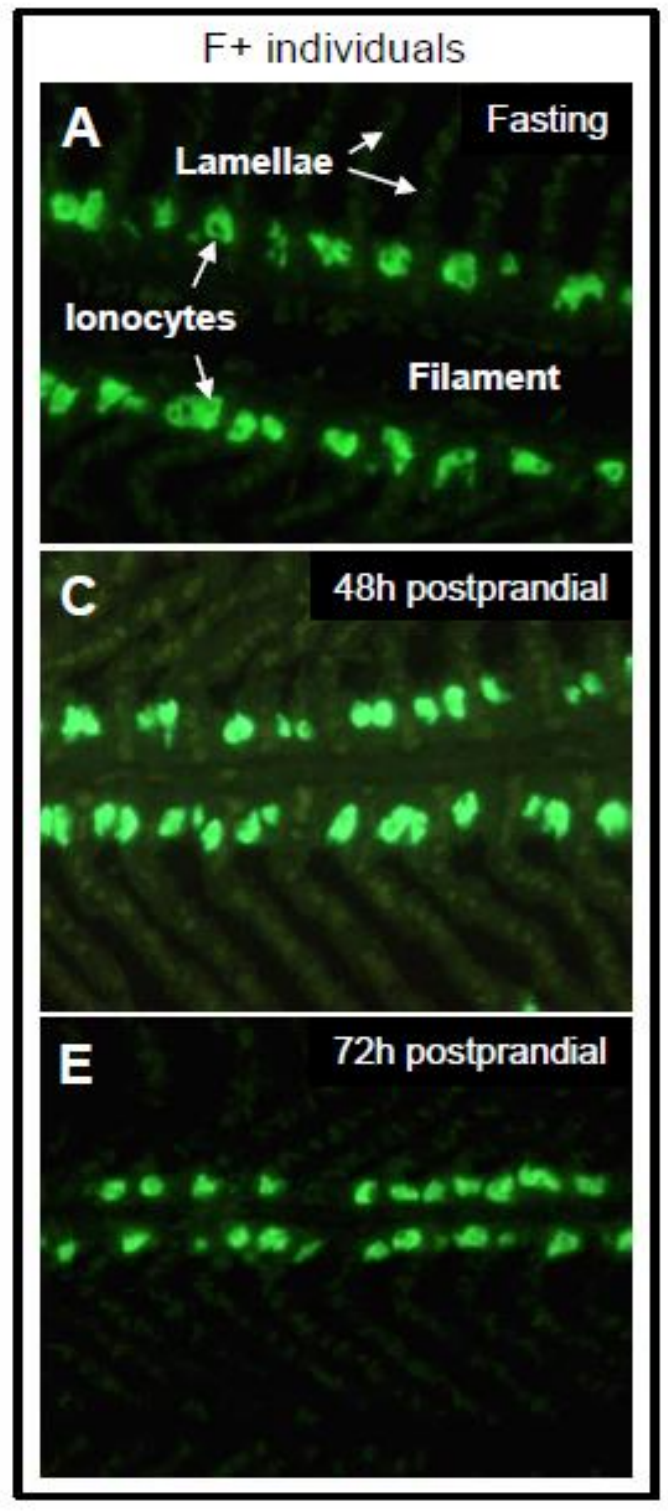

G

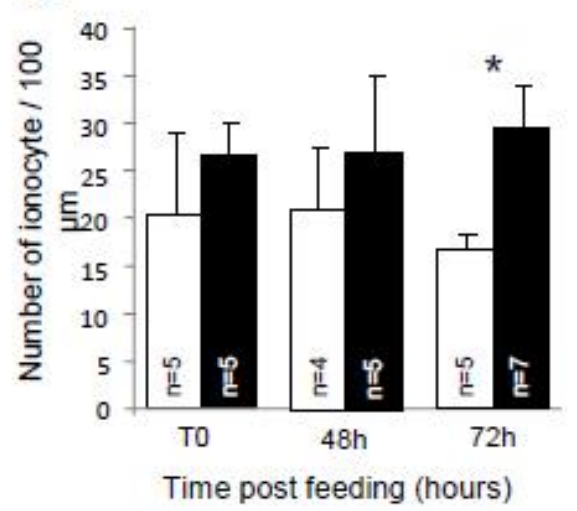

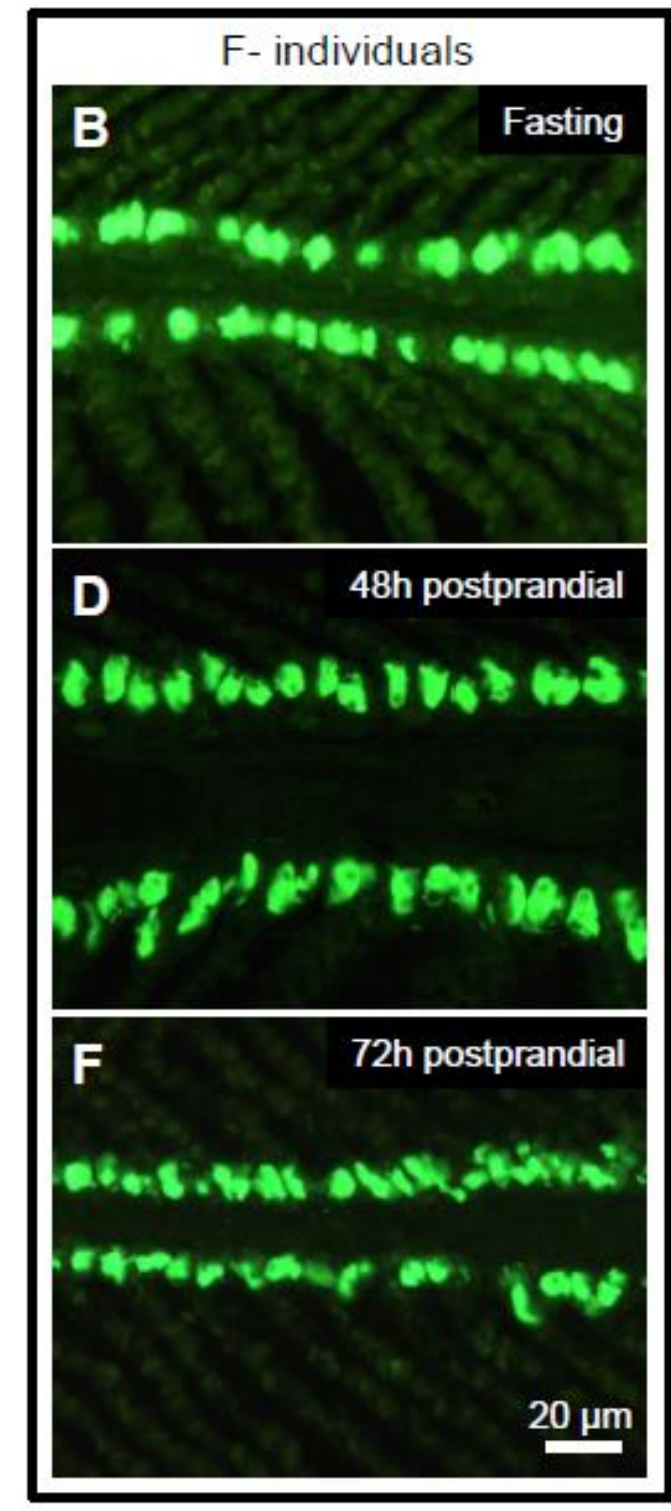

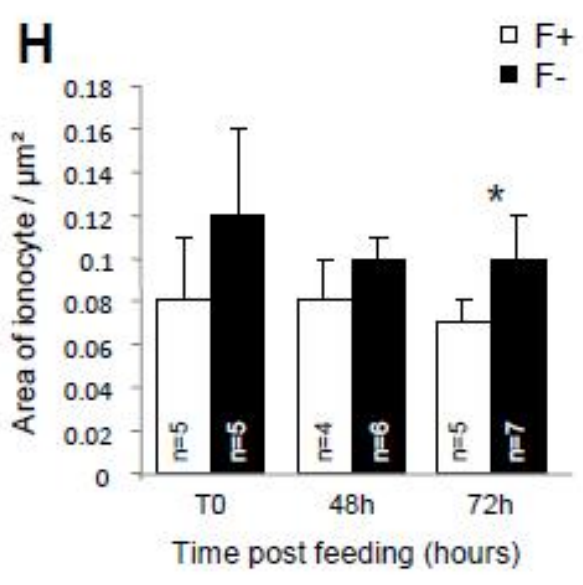


Figure 5
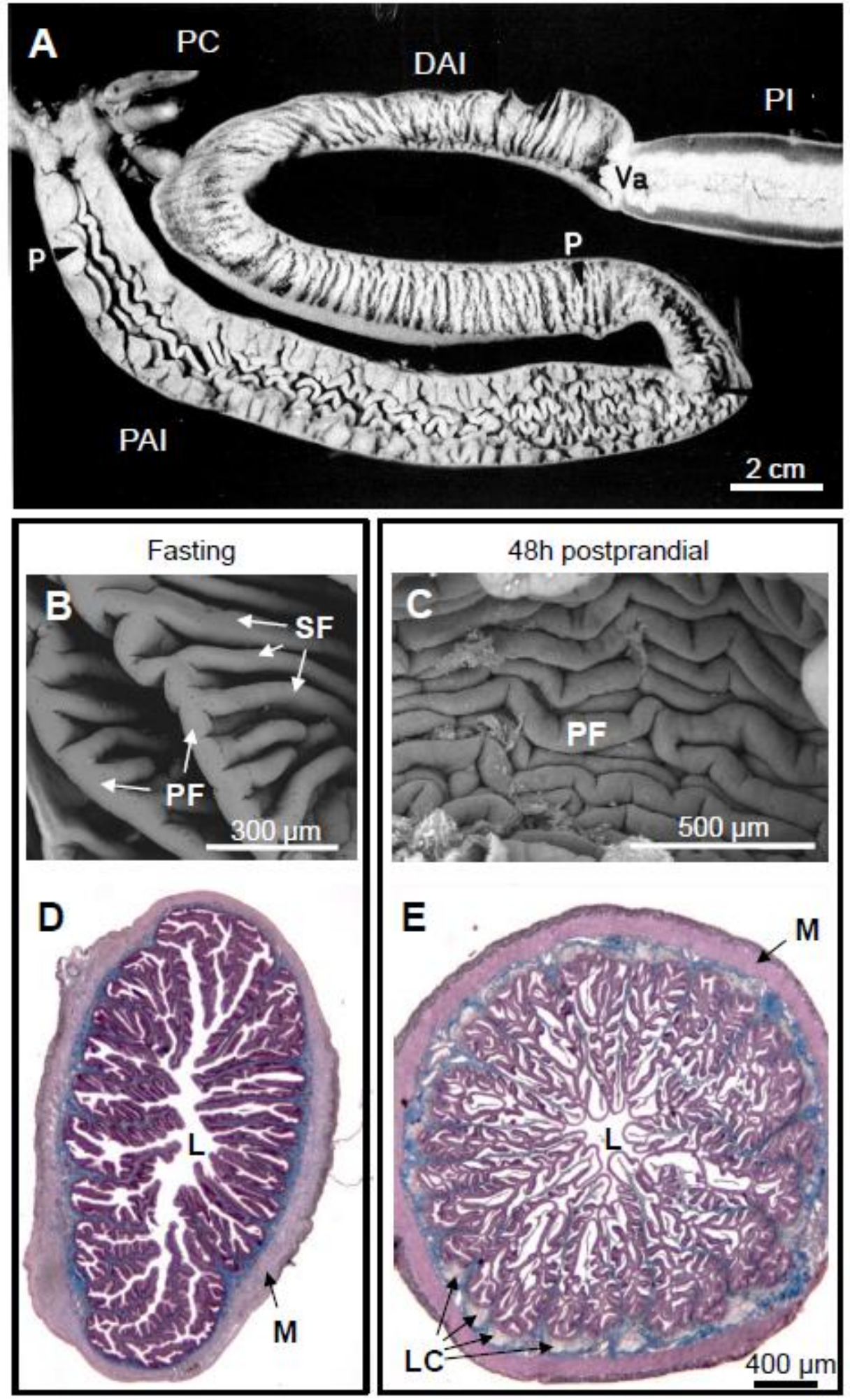


\section{Figure 6}

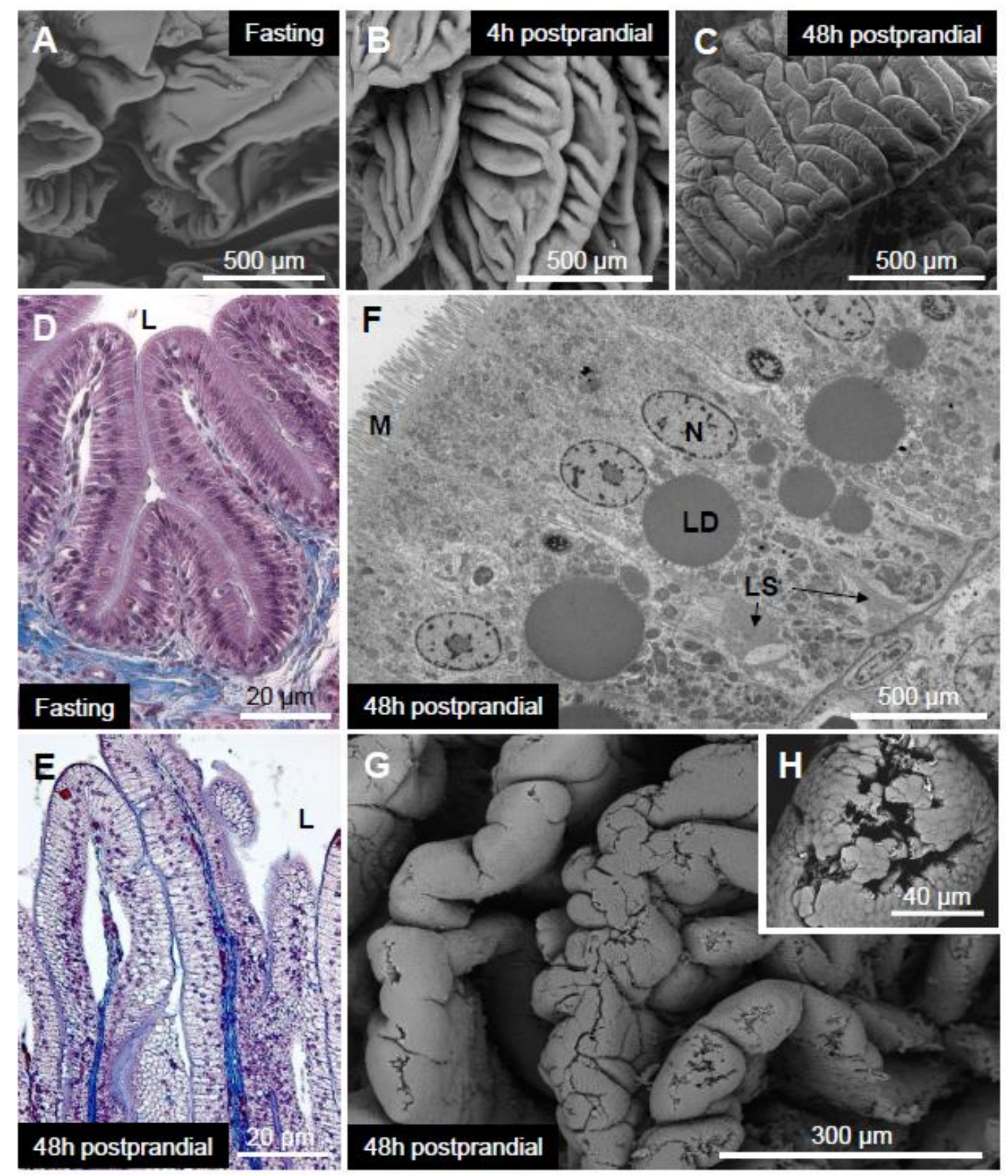




\section{Figure 7}

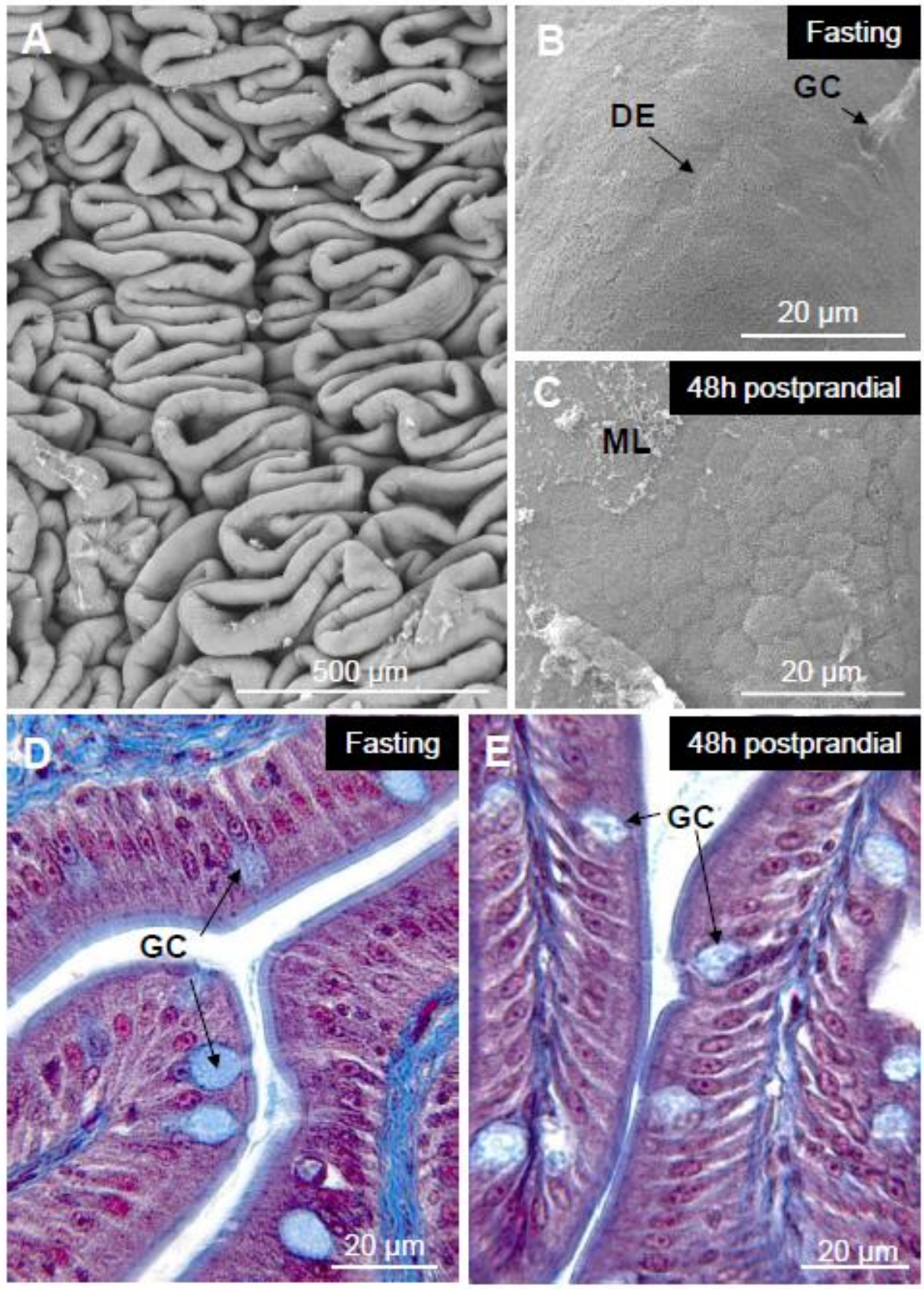




\section{Figure 8}
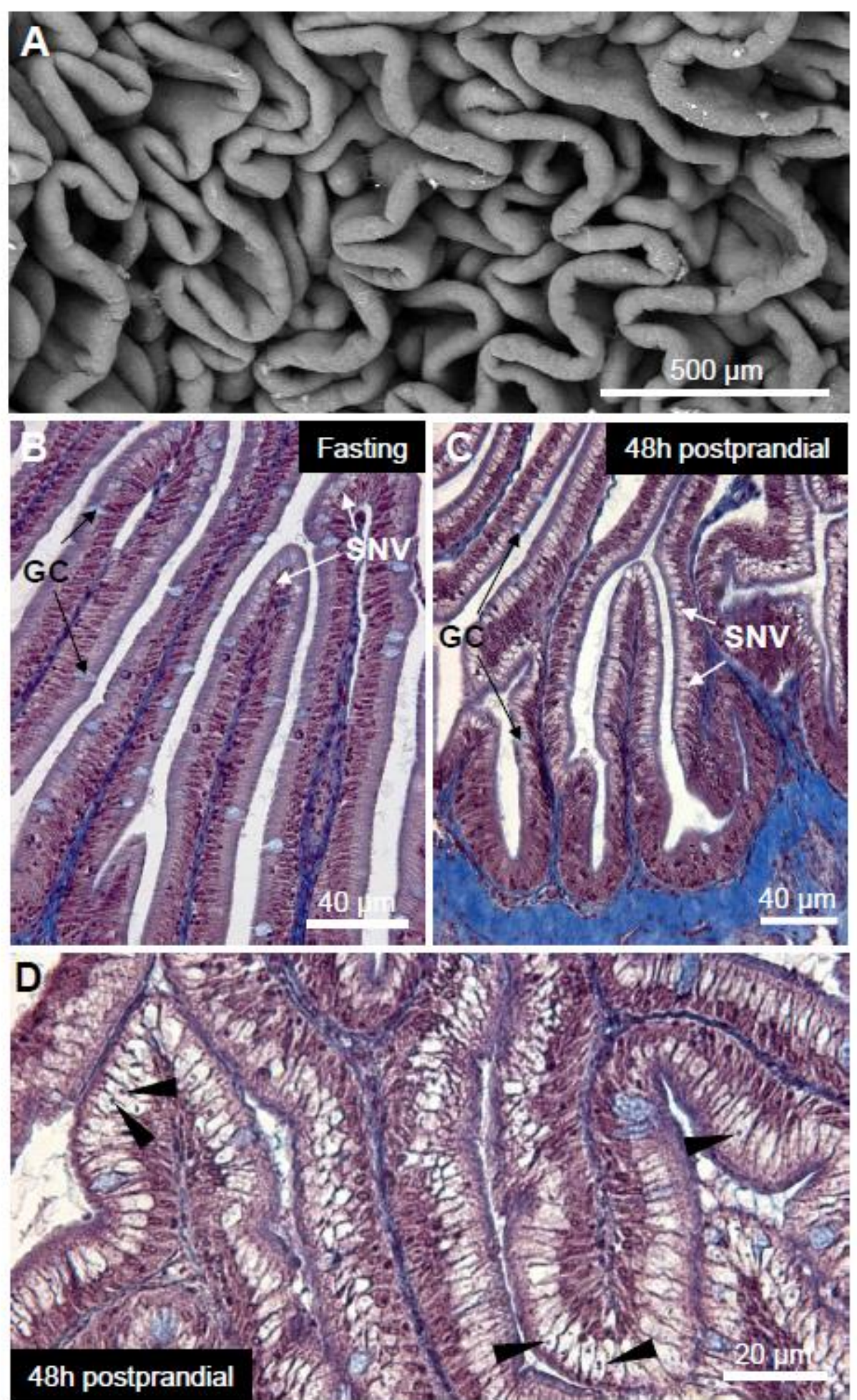
Figure 9
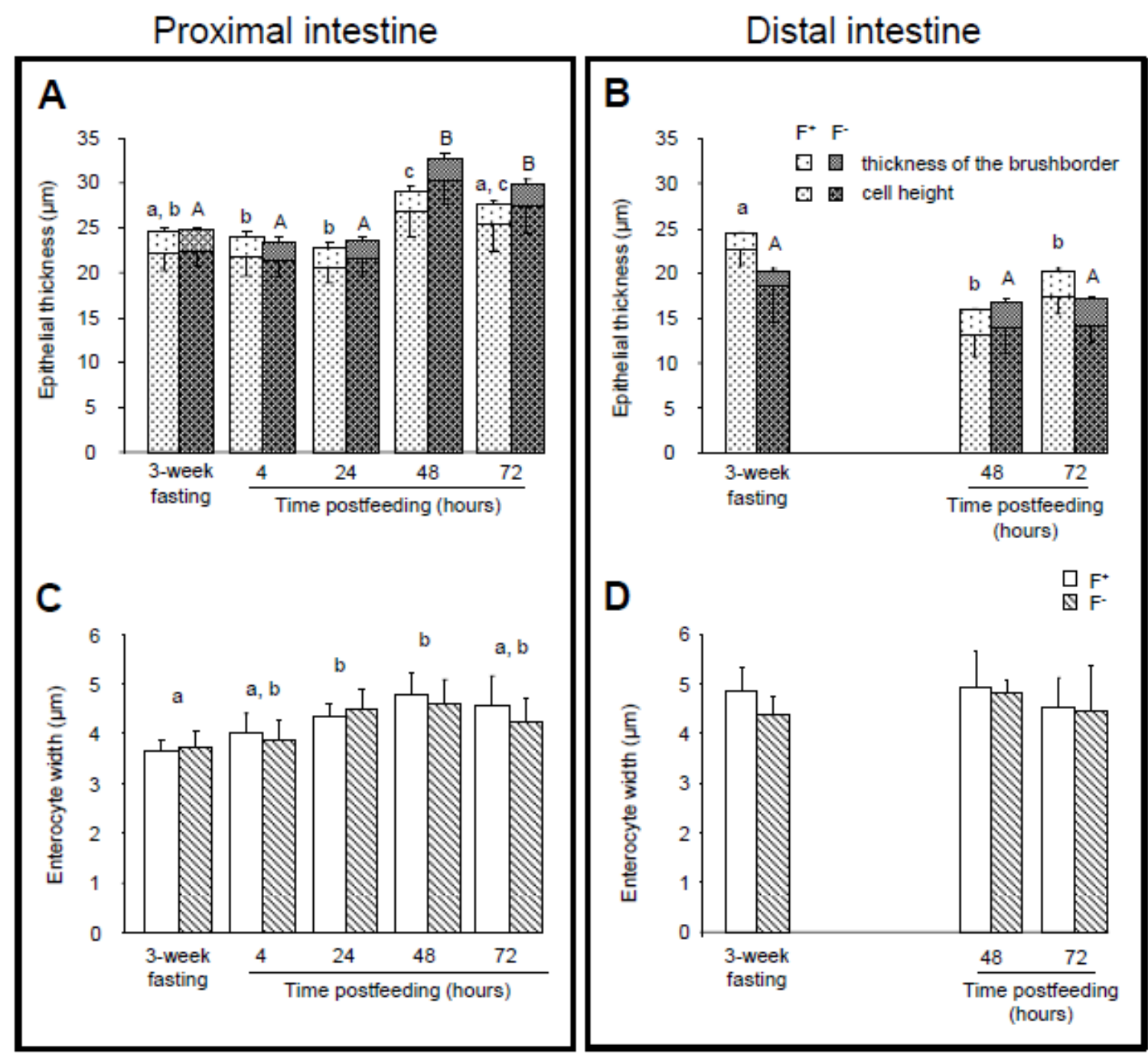